\title{
Clinical Study \\ Clinical Feature of Men Who Benefit from Dose Escalation of Naftopidil for Lower Urinary Tract Symptoms: A Prospective Study
}

\author{
Takaki Mizusawa, ${ }^{1,2}$ Noboru Hara, ${ }^{1,2}$ Kenji Obara, ${ }^{1}$ Etsuko Isahaya, ${ }^{1}$ \\ Yuki Nakagawa, ${ }^{1}$ and Kota Takahashi ${ }^{1}$ \\ ${ }^{1}$ Division of Urology, Department of Regenerative and Transplant Medicine, Graduate School of Medical and Dental Sciences, \\ Niigata University, Asahimachi 1, Niigata 951-8510, Japan \\ ${ }^{2}$ Department of Urology, Kido Hospital, Niigata, Kamikido 5, Niigata 950-0891, Japan
}

Correspondence should be addressed to Noboru Hara, harasho@med.niigata-u.ac.jp

Received 10 December 2010; Revised 31 January 2011; Accepted 11 February 2011

Academic Editor: Flavio Trigo Rocha

Copyright ( 2011 Takaki Mizusawa et al. This is an open access article distributed under the Creative Commons Attribution License, which permits unrestricted use, distribution, and reproduction in any medium, provided the original work is properly cited.

\begin{abstract}
Objectives. To examine the feature of men who benefit from dose escalation of naftopidil for lower urinary tract symptoms (LUTSs). Methods. Based on the IPSS, men reporting LUTS were prospectively studied using $50 \mathrm{mg} /$ day of naftopidil for the first 4 weeks; satisfied patients continued its $50 \mathrm{mg} / \mathrm{day}(n=11)$, and those reporting unsatisfactory improvement received its $75 \mathrm{mg} / \mathrm{day}$ $(n=35)$ for the next 4 weeks. Results. The $75 \mathrm{mg}$ group showed improvement in the total IPSS and QOL score in a dose-dependent manner (at 4 weeks: $P<.001$, at 4 weeks versus 8 weeks: $P<.05$ ). In the $50 \mathrm{mg}$ group, both scores reduced at 4 weeks, thereafter unchanged. The baseline slow stream score alone was higher in the $75 \mathrm{mg}$ group $(P=.013)$. The rate of change in the QOL score during the initial 4 weeks $(\Delta \mathrm{QOL})$ and $\Delta$ nocturia was smaller in the $75 \mathrm{mg}$ group $(P<.05)$. Conclusions. Men with high slow stream score and unsatisfactory improvement in nocturia may benefit from dose escalation of naftopidil.
\end{abstract}

\section{Introduction}

Lower urinary tract symptoms (LUTSs) impair the healthrelated quality of life (QOL) [1-4]. The prevalence and severity of LUTS increase with age, and many middle-aged to elderly people show various levels of LUTS $[4,5]$. Voiding symptoms are more popular in men than in women $[6,7]$, and, correspondingly, the causative condition associated with male LUTS is represented by benign prostatic hyperplasia $(\mathrm{BPH})$. The treatment theory for $\mathrm{BPH}$ is thus targeting voiding symptoms mainly based on two types of lower urinary tract obstruction: mechanical urinary tract obstruction by the enlarged prostate and functional constriction of the urethral and prostatic smooth muscle via sympathetic $\alpha_{1}$ stimulants $/ \alpha_{1}$-adrenoreceptors interaction. Accordingly, $\alpha_{1}$ adrenoreceptor antagonists are widely applied as the first-line in current therapeutic practice for BPH. On the other hand, it is also important to manage not only voiding symptoms but also storage symptoms in men with LUTS. Alpha 1 adrenoceptor antagonists have also been known to alleviate storage symptoms, although the mechanism of storage symptoms as well as how mentioned agents are involved in improvement of them has not been fully elucidated $[3,4,7$, 8].

Naftopidil has a high affinity for $\alpha_{1 \mathrm{D}}$-adrenoceptor; $\alpha_{1}$ adrenoceptor antagonists with high selectivity for $\alpha_{1 \mathrm{~A}}$-adrenoceptors has been thought to be more effective in treatment of LUTS $[8,9]$, whereas recent basic and clinical studies also showed the therapeutic potential of $\alpha_{1}$-adrenoceptor antagonists with high selectivity for $\alpha_{1 \mathrm{D}}$-adrenoceptors [10]. Indeed, naftopidil has been applied for men having BPHassociated LUTS and has been regarded as a secondgeneration $\alpha_{1}$-adrenoceptor antagonist [11]. While $\alpha_{1 \mathrm{~A}}$-adrenoceptors play a critical role in relaxing smooth muscle of the prostate and urethra and improve obstructive/voiding symptoms $[8,9]$, storage and bladder irritability symptoms 
are predominantly $\alpha_{1 \mathrm{D}}$-adrenoceptor-associated conditions [10]. Although unfavorable/adverse effects by naftopidil on blood pressure/cardiovascular system are infrequent, $50 \mathrm{mg} /$ day of peroral naftopidil is the initial treatment setting in Asian populations generally [11]. A recent case-control study reported that the setting of $75 \mathrm{mg}$ /day showed a higher therapeutic efficacy compared with that of 25 or $50 \mathrm{mg} /$ day of naftopidil $[11,12]$. Yet, there have been few studies that examined the treatment efficacy and safety of $75 \mathrm{mg} /$ day of peroral naftopidil in longitudinal comparison with those of $50 \mathrm{mg} /$ day; such approach may possibly characterize patients who benefit from dose escalation of naftopidil without compromising safety in clinical practice. Thereby, key/leading symptoms or factors impairing LUTSrelated QOL may be underscored. In the present study, we prospectively studied men having moderate-to-severe LUTS in a longitudinal approach with dose escalation from $50 \mathrm{mg}$ to $75 \mathrm{mg}$ of naftopidil once a day to examine the feature of patients who prefer and benefit from dose escalation of naftopidil, and to identify which symptom and improvement thereof reflect the LUTS-related QOL.

\section{Methods}

2.1. Patients. In total, 53 patients who presented at Niigata University Hospital and associated institutions with the International Prostate Symptom Score (IPSS) of 8 or higher were prospectively enrolled between September 2007 and July 2009. The performance status was good (World Health Organization Performance Status Score zero) in all of them. The study had a longitudinal design, and the procedure for this research project was approved by the Ethics Committee of our institution. Informed consent was obtained from all of the patients. Exclusion criteria were patients with a history of bladder cancer, prostate cancer, or pelvic irradiation, along with those diagnosed with bladder stone, untreated definite urinary tract infections, and neurogenic bladder. Patients who had already been treated for lower urinary tract dysfunctions with surgery or any intervention were also excluded.

2.2. Examinations and Questionnaires. At the initial visit, the patients filled in the baseline International Prostate Symptom Score (IPSS) sheets handed to them when visiting the outpatient clinic. General blood and biochemical examinations, urinalysis, residual urine volume measurement using an ultrasonographic instrument, and ultrasonographic examinations of the upper and lower urinary tracts were performed in all patients. Those with microscopic hematuria received a urinary cytological examination; all of them showed a normal smear.

\subsection{Dose Escalation of Naftopidil and Longitudinal Assessment} of IPSS. All patients were treated with $50 \mathrm{mg}$ of naftopidil once a day for the first 4 weeks and reported the IPSS after administration. Patients without adverse events who reported unsatisfactory improvement of LUTS and preferred advanced treatment based on a question "are you satisfied with your current urinary state, yes or no?" received $75 \mathrm{mg}$ of naftopidil once a day for the next 4 weeks ( $75 \mathrm{mg}$ group) and reported the IPSS again following treatment ( 8 weeks after starting treatment). Those having satisfactory improvement with the initial treatment at $50 \mathrm{mg} /$ day continued $50 \mathrm{mg}$ of naftopidil (50 mg group) and also reported IPSS in the next 4 weeks ( 8 weeks after starting treatment). Adverse events were assessed at every visit.

2.4. Statistical Analysis. In addition to the chi-square test and pared $t$-test, the Welch-corrected $t$-test was used to compare unpaired parameters between two subgroups, and Tukey's honestly significant difference (HSD) was used for the comparison of values among 3 or more subgroups. Correlations between parameters were analyzed using Spearman's rank correlation coefficient analysis (rs). Multilinear logistic regression model, which produces prediction formula with a smaller margin of error, was used for the identification of independent significant correlations among continuous or stepwise variables. The test was two-sided, and $P<$ .05 was considered significant. All analyses were performed using SPSS version 11.0J (SPSS Inc., Chicago, IL, USA) in a Windows-based computer.

\section{Results}

3.1. Adverse Events and Patients' Demographics. Data were available in 53 patients, and, of these, treatment was discontinued due to adverse effects at the dose of $50 \mathrm{mg} /$ day and $75 \mathrm{mg} /$ day in 5 and 2 patients ( $9.4 \%$ and $5.4 \%$ ), respectively, at $50 \mathrm{mg}$ : dizziness in 2 , slight stagger in 1 , orthostatic hypotension in 1, and orthostatic syncope in 1, and the events soon disappeared by drug discontinuation; at $75 \mathrm{mg}, 2$ patients reported slight stagger, and these disappeared soon after dose reduction to $50 \mathrm{mg}$. Excluding these subjects, 46 patients comprised the final study groups, and 35 and 11 men were included in the $75 \mathrm{mg}$ and $50 \mathrm{mg}$ groups, respectively. Demographics and the baseline IPSS of the patients were shown in Table 1. Patients' age, prostate volume, residual urine volume, total IPSS, and storage, voiding, and qualityof-life (QOL) scores were equally distributed between the $75 \mathrm{mg}$ and $50 \mathrm{mg}$ groups (Table 1). For each domain of the baseline IPSS, the score for slow stream alone was higher in the $75 \mathrm{mg}$ group than in the $50 \mathrm{mg}$ group $(3.6 \pm 1.6$ versus $2.1 \pm 1.9, P=.013)$.

\subsection{Alteration of the IPSS and QOL Score during the Obser-} vation Period. The alteration of the total IPSS, storage score, voiding score, postmicturition score (domain for feeling of incomplete emptying), and QOL score was presented in Figures 1(a)-1(e). The $75 \mathrm{mg}$ group showed improvement in all of these in a time-dependent and dose-dependent manner (baseline versus 4 weeks after treatment: $P<.001$ in all; 4 weeks after treatment versus 8 weeks after treatment: $P=$ $.019, P=.057, P=.047, P=.057$, and $P=.003$, resp.), although the difference in the storage and postmicturition scores were of borderline significance between at 4 weeks and 8 weeks (Figures $1(\mathrm{~b})$ and $1(\mathrm{~d})$ ). In the $50 \mathrm{mg}$ group, 


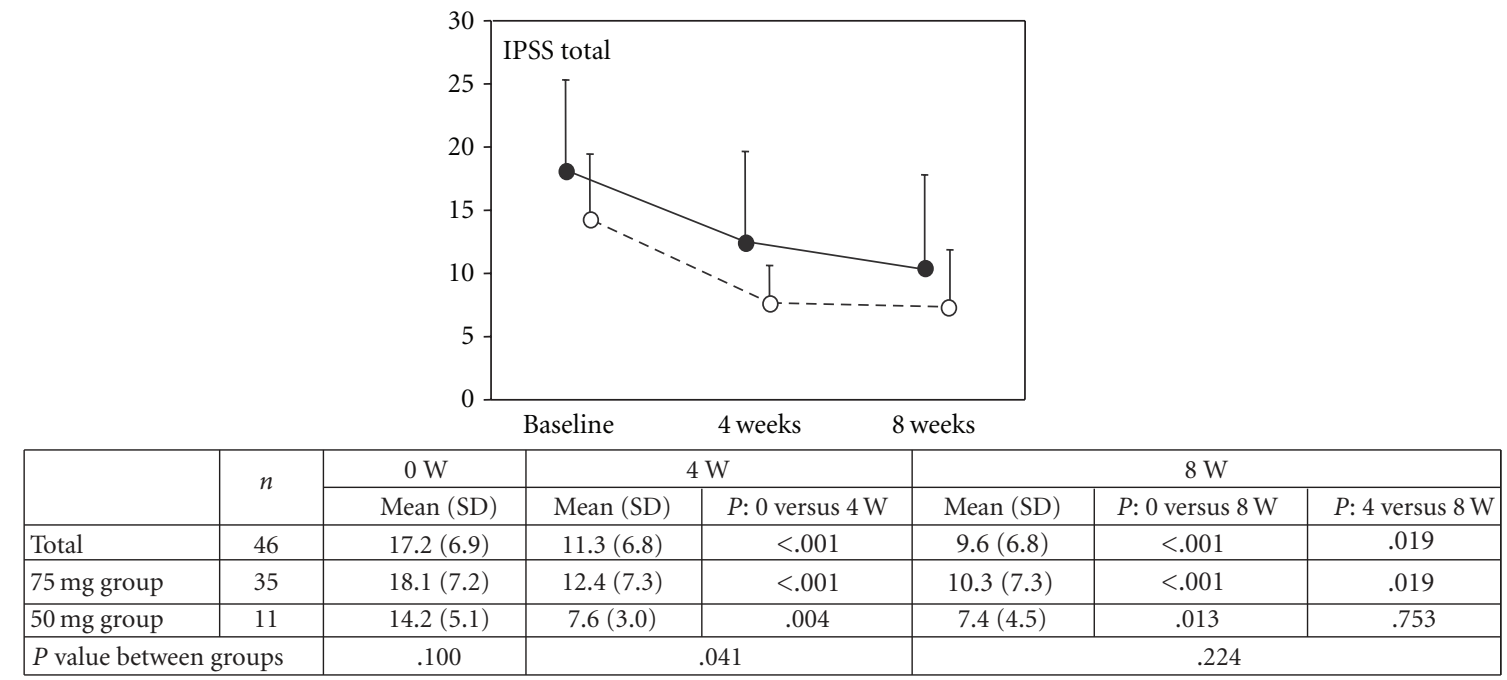

(a)

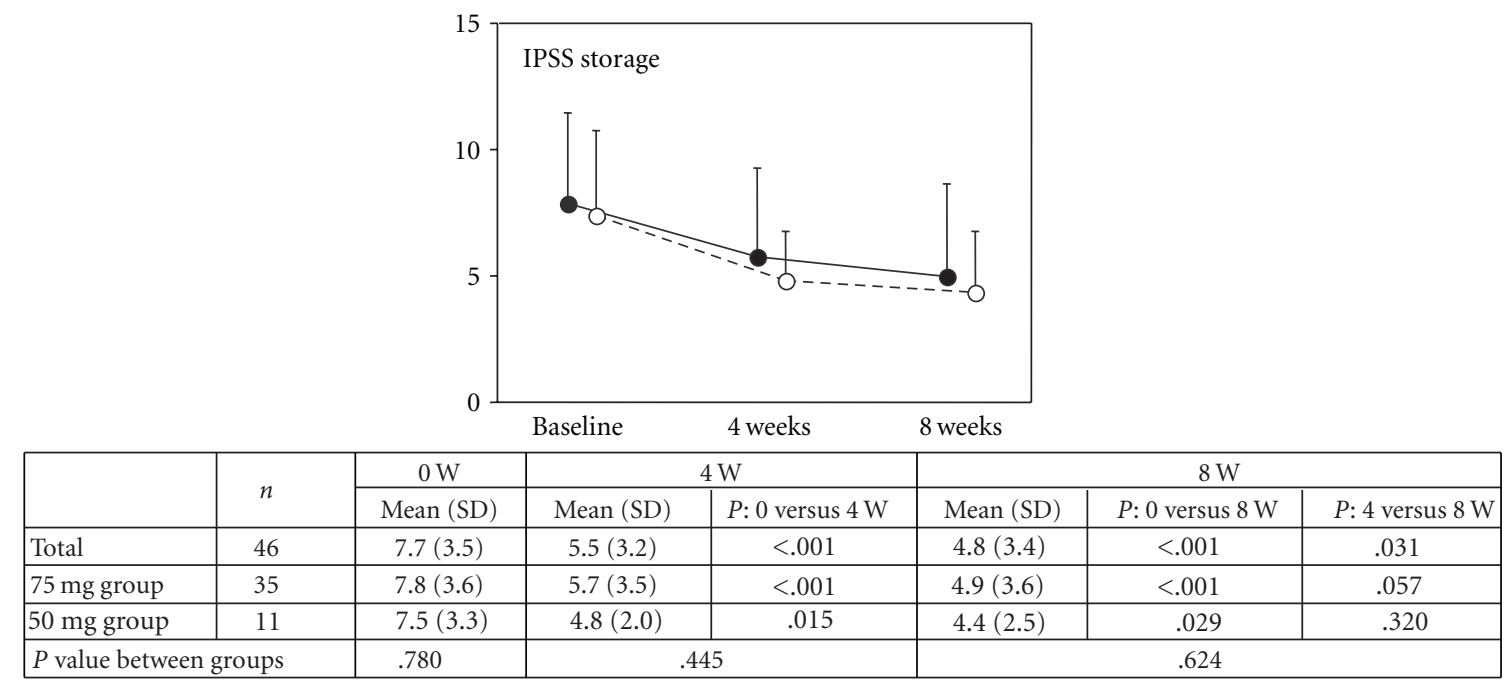

(b)

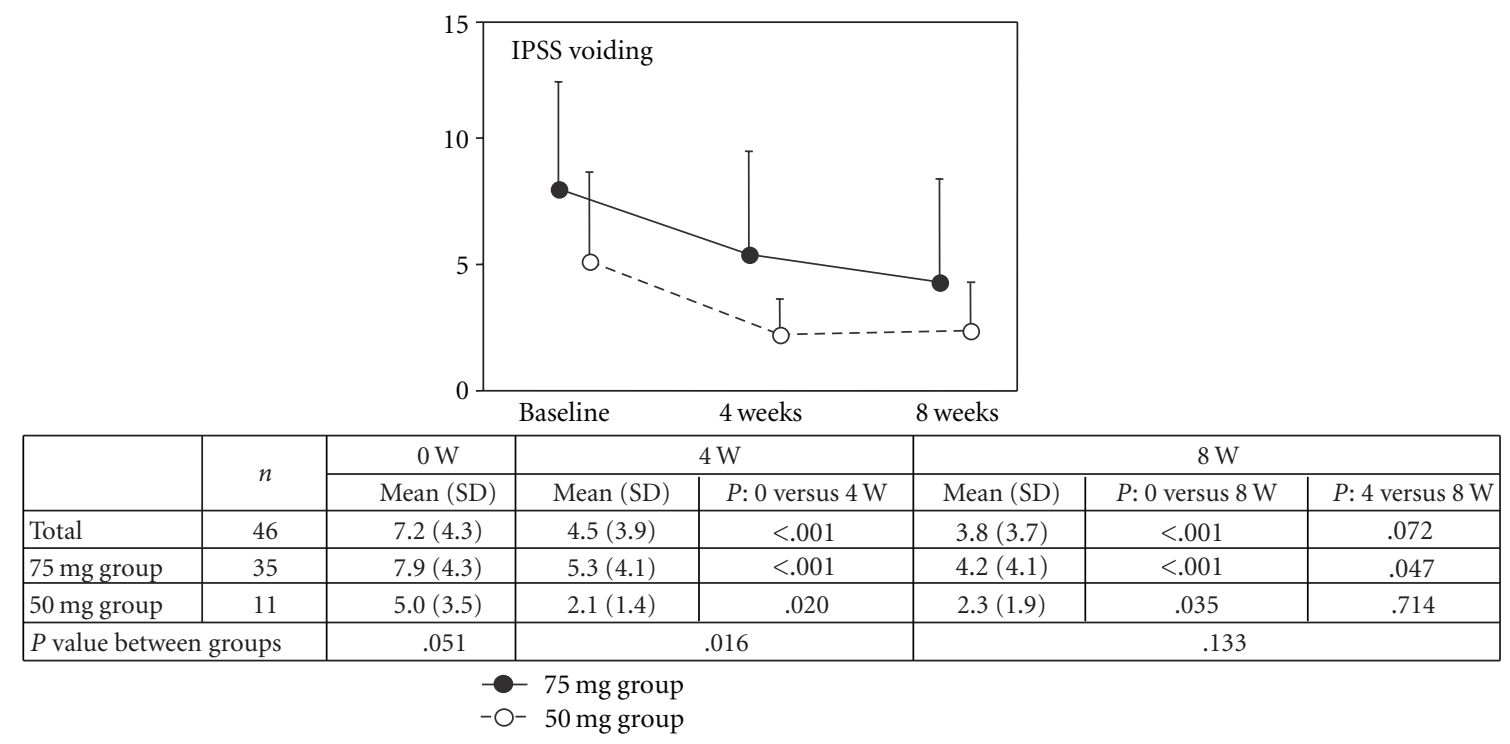

(c)

FIgUre 1: Continued. 


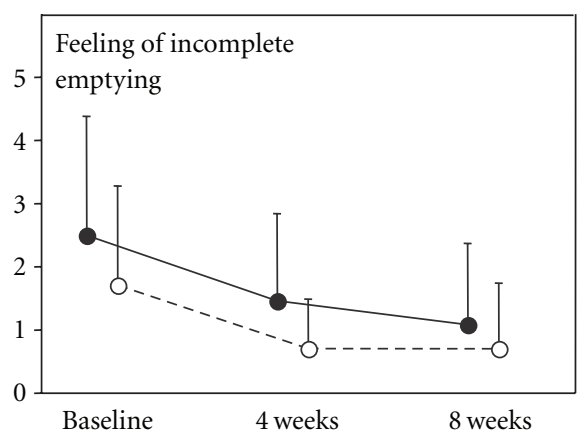

\begin{tabular}{|l|c|c|c|c|c|c|c|}
\hline \multirow{2}{*}{} & \multirow{2}{*}{$n$} & $0 \mathrm{~W}$ & \multicolumn{2}{|c|}{$4 \mathrm{~W}$} & \multicolumn{3}{c|}{$8 \mathrm{~W}$} \\
\cline { 2 - 8 } & & Mean (SD) & Mean (SD) & $P: 0$ versus 4 W & Mean (SD) & $P: 0$ versus 8 W & $P: 4$ versus 8 W \\
\hline Total & 46 & $2.3(1.8)$ & $1.3(1.3)$ & $<.001$ & $1.0(1.2)$ & $<.001$ & .063 \\
\hline 75 mg group & 35 & $2.5(1.9)$ & $1.5(1.4)$ & $<.001$ & $1.1(1.3)$ & $<.001$ & .057 \\
\hline 50 mg group & 11 & $1.7(1.6)$ & $0.7(0.8)$ & .041 & $0.7(1.0)$ & .049 & .999 \\
\hline$P$ value between groups & .233 & \multicolumn{7}{|c|}{.108} \\
\hline
\end{tabular}

(d)

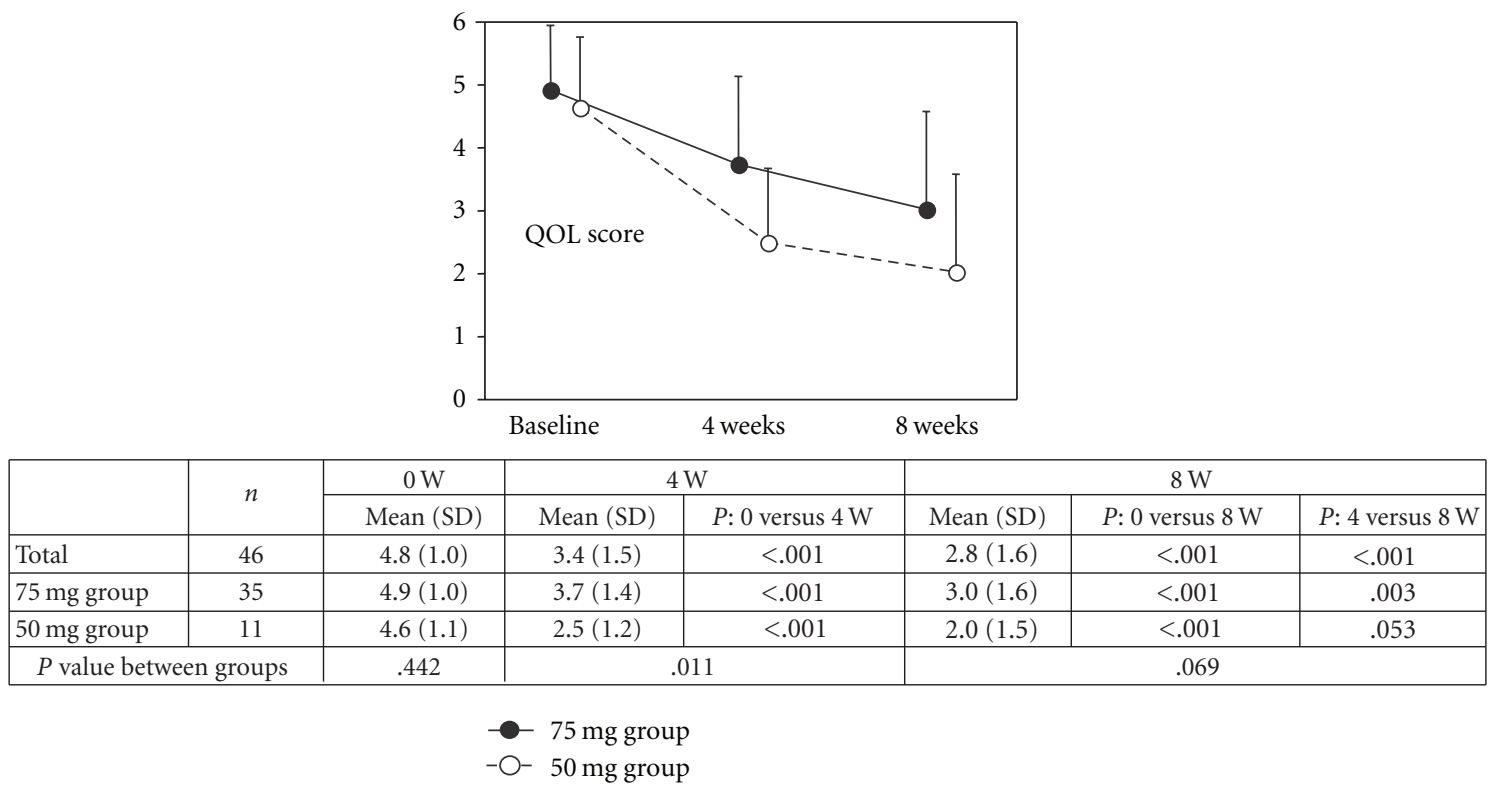

(e)

FIGURE 1: Alteration of the total IPSS (a), storage (b), voiding (c), postmicturition (domain for feeling of incomplete emptying) (d), and QOL (e) scores in men with dose escalation from $50 \mathrm{mg} /$ day to $70 \mathrm{mg}$ /day of naftopidil ( $75 \mathrm{mg}$ group) and those maintained with its $50 \mathrm{mg} / \mathrm{day}$ (50 mg group).

all of these scores reduced 4 weeks after treatment compared with those at baseline $(P=.004, P=.015, P=.020$, $P=.041$, and $P<.001$, resp.); these scores were not different between 4 weeks and 8 weeks after treatment (Figures 1(a)$1(\mathrm{e}))$, although the difference was of borderline significance regarding the QOL score $(P=.053)$.

3.3. Analyses Concerning the Feature of the $75 \mathrm{mg}$ Group. We further studied the clinical feature of men in the $75 \mathrm{mg}$ group in comparison with the $50 \mathrm{mg}$ group to identify those who benefit from $75 \mathrm{mg}$ treatment. We hypothesized that the low degree of satisfaction concerning some specific symptoms with $50 \mathrm{mg} /$ day of naftopidil might be associated with the motive for patients to select the dose escalation. We first verified that the rate of change in the QOL score during the initial 4 weeks $(\triangle \mathrm{QOL})$ in the $75 \mathrm{mg}$ group was smaller than that in the $50 \mathrm{mg}$ group ( $P=.045$, Figure 2 , right side columns). We subsequently analyzed the rate of change in each domain of the IPSS during the initial 4 weeks to examine which $\Delta$ domain potentially reflected $\Delta \mathrm{QOL}$, and found that the rate of change in nocturia ( $\Delta$ nocturia) alone was smaller in the $75 \mathrm{mg}$ group than in the $50 \mathrm{mg}$ group $(P=.046$, Figure 2$)$. With Spearman's rank correlation coefficient analysis, the baseline score for nocturia was correlated with the QOL score in the overall patients ( $\mathrm{rs}$. $=0.459, P=.002$ ) and in the $75 \mathrm{mg}$ group (rs. $=0.462, P=.007$ ), but the relationship 
TABle 1: Patients' demographics and the baseline International Prostate Symptom Score (IPSS).

\begin{tabular}{lcccc}
\hline & $\begin{array}{c}\text { Total } \\
(n=46)\end{array}$ & $\begin{array}{c}75 \mathrm{mg} \text { group } \\
(n=35)\end{array}$ & $\begin{array}{c}50 \mathrm{mg} \text { group } \\
(n=11)\end{array}$ & $\begin{array}{c}P \text { value } \\
(75 \mathrm{mg} \text { versus 50 mg })\end{array}$ \\
\hline Age, mean (years) & $71.7 \pm 9.4$ & $72.1 \pm 9.2$ & $70.2 \pm 10.5$ & .559 \\
Prostate volume, mean $(\mathrm{mL})$ & $31.7 \pm 24.8$ & $34.6 \pm 24.9$ & $25.0 \pm 24.8$ & .403 \\
Residual urine, mean $(\mathrm{mL})$ & $24.0 \pm 41.5$ & $24.5 \pm 43.3$ & $22.4 \pm 36.1$ & .899 \\
IPSS total & $17.2 \pm 6.9$ & $18.1 \pm 7.2$ & $14.2 \pm 5.1$ & .100 \\
$\quad$ Storage score & $7.7 \pm 3.5$ & $7.8 \pm 3.6$ & $7.5 \pm 3.3$ & .780 \\
$\quad 3.0 \pm 1.6$ & $3.1 \pm 1.6$ & $2.8 \pm 1.8$ & .602 \\
$\quad$ Pollakisuria & $1.9 \pm 1.8$ & $2.0 \pm 1.9$ & $1.5 \pm 1.4$ & .469 \\
$\quad$ Urgency & $2.8 \pm 1.3$ & $2.7 \pm 1.3$ & $3.1 \pm 1.4$ & .385 \\
$\quad$ Nocturia & $7.2 \pm 4.3$ & $7.9 \pm 4.3$ & $5.0 \pm 3.5$ & .051 \\
$\quad$ Voiding score & $2.2 \pm 1.9$ & $2.4 \pm 2.0$ & $2.1 \pm 1.9$ & .334 \\
$\quad$ Intermittency & $3.2 \pm 1.8$ & $3.6 \pm 1.6$ & $1.2 \pm 1.3$ & .013 \\
$\quad$ Slow stream & $1.7 \pm 1.8$ & $1.9 \pm 1.9$ & $1.7 \pm 1.6$ & .242 \\
$\quad$ Postmicturition score* & $2.3 \pm 1.8$ & $2.5 \pm 1.9$ & $4.6 \pm 1.1$ & .442 \\
QOL score & $4.8 \pm 1.0$ & $4.9 \pm 1.0$ & \\
\hline
\end{tabular}

Score: mean \pm standard deviation (SD); postmicturition score*, domain for feeling of incomplete emptying.

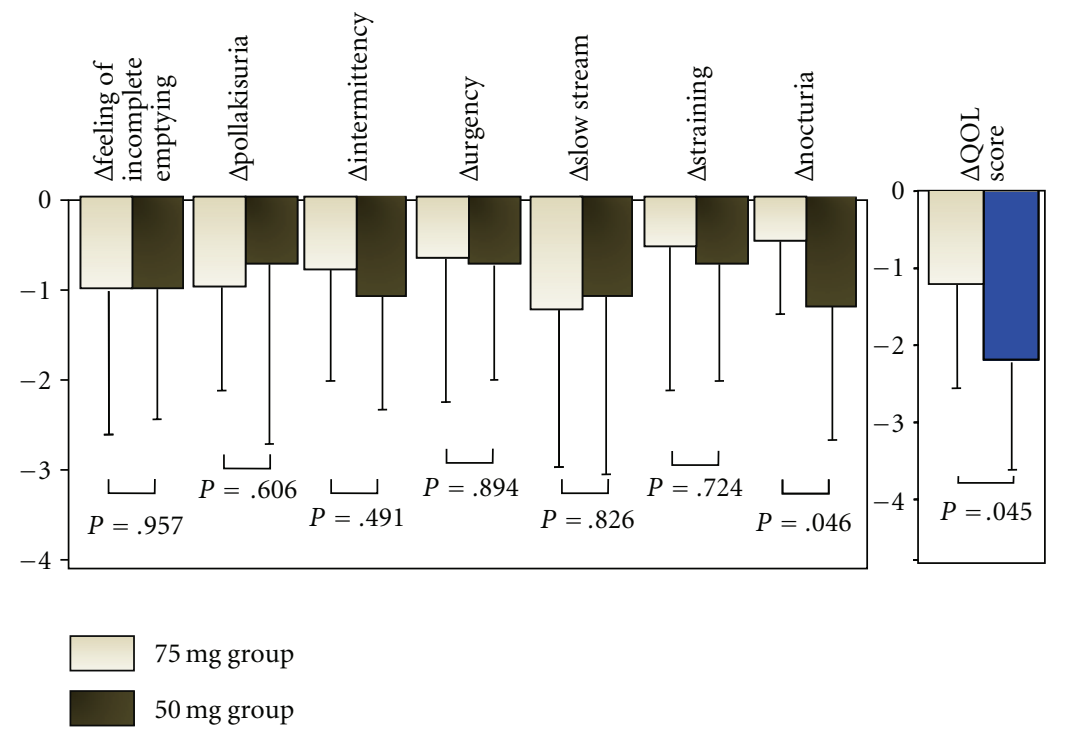

FIGURE 2: The rate of change in the QOL score ( $\triangle \mathrm{QOL}$ ) and each domain of the IPSS ( $\Delta$ each domain) with $50 \mathrm{mg} / \mathrm{day}$ of naftopidil during the first 4 weeks.

was not significant in the $50 \mathrm{mg}$ group despite the high correlation coefficient (rs. $=0.482, P=.127$ ). The score for nocturia 4 weeks after treatment was also correlated with the QOL score in the overall patients (rs. $=0.459, P=.002$ ) and in the $75 \mathrm{mg}$ group ( $\mathrm{rs} .=0.475, P=.006$ ); the relationship was not significant in the $50 \mathrm{mg}$ group with the high correlation coefficient ( $\mathrm{rs} .=0.508, P=.108) . \Delta$ nocturia was correlated with $\triangle$ QOL in the overall patients (rs. = $0.562, P<.001)$ and both in the $75 \mathrm{mg}$ and $50 \mathrm{mg}$ groups (rs. $=0.437, P=.011$ and rs. $=0.663, P=.036$, resp.). With multivariate analysis employing multilinear logistic regression model, $\Delta$ nocturia alone was an independent value correlated with $\triangle \mathrm{QOL}$ in all 46 patients $(r=0.542, P=$ .006). In each group, however, this model failed to identify significant independent correlations (data not shown).

\section{Discussion}

Funahashi and colleagues reported the efficacy of $75 \mathrm{mg} / \mathrm{day}$ of naftopidil in patients with BPH who did not show improvement with $50 \mathrm{mg} /$ day of naftopidil [12]. In their study, 40 of the 122 patients received $75 \mathrm{mg} /$ day of naftopidil; prostate volume of the 9 responders was larger than that of the 31 nonresponders, and the authors concluded possible advantage of the dose escalation to $75 \mathrm{mg} /$ day of naftopidil in patients with $\mathrm{BPH}$. The present study design was similar to that of Funahashi et al. [12] , but, in our study, a higher fraction of patients $(76 \%)$ experienced dose escalation based on the satisfaction in improvement of LUTS. We showed that the total IPSS, storage, voiding, postmicturition, and QOL scores in the $75 \mathrm{mg}$ group decreased in a time-dependent 
and dose-dependent manner, although the difference in the postmicturition and storage scores was of borderline significance between at 4 weeks and 8 weeks (Figure 1(a)$1(\mathrm{e}))$. In the $50 \mathrm{mg}$ group, these scores were similar between 4 weeks and 8 weeks after treatment, possibly suggesting dosedependent rather than time-dependent effects of naftopidil in the $75 \mathrm{mg}$ group; the number of patients enrolled in the $50 \mathrm{mg}$ group was small to draw a definite conclusion. Additionally, adverse effects did not differ between the two settings, supporting the safety of $75 \mathrm{mg} /$ day of this agent.

The present results showed that patients selecting $75 \mathrm{mg}$ therapy had higher scores for the slow stream domain at baseline (mean 3.6, Table 1), and those with a baseline score of 3 or higher for slow stream are probably feasible candidates who benefit from dose escalation of naftopidil. Additionally, the $75 \mathrm{mg}$ group seemingly had a higher IPSS voiding score at baseline and larger prostate volume than the $50 \mathrm{mg}$ group; the small number of patients in the $50 \mathrm{mg}$ group might lead to the bias. Thus, it is suggested that severer bladder outlet resistance was associated with unsatisfactory improvement of symptoms during $50 \mathrm{mg}$ treatment in the $75 \mathrm{mg}$ group. Naftopidil also has an $\alpha_{1 \mathrm{~A}}$ adrenogenic activity, although it is weaker than that of other $\alpha_{1}$-adrenoreceptor antagonists such as tamsulosin. Naftopidil is $\alpha_{1}$-adrenoreceptor selective in the order of $\alpha_{1 \mathrm{D}}>\alpha_{1 \mathrm{~A}} \geq \alpha_{1 \mathrm{~B}}$, and it has about 3 -fold selectivity for $\alpha_{1 \mathrm{D}}$-adrenoreceptors compared with that for $\alpha_{1 \mathrm{~A}^{-}}$ adrenoreceptors [8], suggesting that dose escalation of naftopidil possibly could evoke more $\alpha_{1 \mathrm{~A}}$-adrenoreceptor reactions in relaxing the prostate/urethra smooth muscle and alleviating voiding symptoms. For men with bladder outlet obstruction or reporting moderate-to-severe voiding symptoms, the initial appropriate dose of naftopidil may be $75 \mathrm{mg} /$ day.

Our study also suggested the dose-dependent efficacy of naftopidil for storage symptoms in the $75 \mathrm{mg}$ groups (Figure 1(b)), although the difference was of borderline significance between 4 weeks and 8 weeks after treatment. Interestingly, analyses for the degree of satisfaction showed that $\triangle Q O L$ during the first 4 weeks with $50 \mathrm{mg} /$ day of naftopidil in the $75 \mathrm{mg}$ group was smaller than that in the $50 \mathrm{mg}$ group $(P=.045$, Figure 2$)$ and that $\Delta$ nocturia during the first 4 weeks may possibly be an important parameter for the degree of satisfaction $(P=.046$, Figure 2$)$. We moreover verified the correlation between the QOL and nocturia scores at baseline or 4 weeks after $50 \mathrm{mg}$ treatment with Spearman's rank correlation coefficient analysis in the overall patients and $75 \mathrm{mg}$ group, but it was not significant in the $50 \mathrm{mg}$ group. We could not draw a definite conclusion concerning this result in the $50 \mathrm{mg}$ group due to the small number of patients, however; $\Delta$ nocturia was correlated with $\Delta \mathrm{QOL}$ both in the $75 \mathrm{mg}$ and $50 \mathrm{mg}$ groups (rs. $=0.437, P=.011$ and rs. $=0.663, P=.036$, resp.). These results also suggest the possible importance of improvement in nocturia for improvement in QOL by naftopidil. Effectiveness of naftopidil at a high dose for voiding symptoms can be explained by pharmacokinetics/pharmacodynamics of the agent in vivo and its effect on $\alpha_{1}$-adrenoceptor antagonists $/ \alpha_{1}$ adrenoreceptors interaction [13]. Storage symptoms are con- sidered to represent those of $\mathrm{BPH}$-related overactive bladder [14], and most recent basic studies on $\alpha_{1}$-adrenoceptor antagonists $/ \alpha_{1}$-adrenoreceptors in the lower urinary tract may account for the dose-dependent efficacy of naftopidil for improving storage symptoms [14, 15]. Unfortunately, our study cannot clarify the reason for improved storage symptoms including nocturia with naftopidil; the complexity of the mechanism of nocturia made us refrain from explicating this phenomenon [16]. The smaller voiding score and prostate volume in the $50 \mathrm{mg}$ group suggests another possible difference in the etiology of LUTS between the two groups; LUTS in the $50 \mathrm{mg}$ group may be associated with bladderrelated conditions. As described elsewhere, naftopidil is an agent with relatively high selectivity for $\alpha_{1 \mathrm{D}}$-adrenoreceptors [17]. It has been reported that not only $\alpha_{1 \mathrm{~A}^{-}}$but also $\alpha_{1 \mathrm{D}^{-}}$ adrenoreceptor antagonists effectively treat male LUTS and $\mathrm{BPH}$-related symptoms, but the $\alpha_{1 \mathrm{D}}$-relevant mechanism has not been fully elucidated. Urinary-function-related $\alpha_{1 D^{-}}$ adrenoreceptors are distributed in the prostate, bladder, and spinal cord [17]. Alpha ${ }_{1}$-adrenoreceptors most frequently expressed in the human bladder are the $\alpha_{1 D}$-type, which has recently been regarded as an important subtype associated with LUTS [17]. In a bladder outlet obstruction model using rats, the increase in bladder detrusor muscle was associated with the higher expression of $\alpha_{1 \mathrm{D}}$-adrenoreceptors both in mRNA and protein levels [18]. In another study on the central nervous system, intrathecally injected naftopidil reduced the intensity of bladder constriction in rats, suggesting the relevance of $\alpha_{1 \mathrm{D}}$-adrenoreceptors in the spinal cord center [19]. With frequency/volume analysis and filling cystometry in $\alpha_{1 \mathrm{D}}$ knockout mice, Chen and colleagues reported that $\alpha_{1 \mathrm{D}}$-adrenoreceptor subtype plays a critical role in regulating bladder function, theoretically supporting clinical observations such as effectiveness of naftopidil for treating storage symptoms [20]. Further clinical and basic approaches are thus warranted to elucidate the various effects of this agent.

The present study had several limitations. The small number of participants in the current study led to a limited capacity. Randomized double-blind studies in a large volume could have provided higher data quality supported by a higher evidence level. Also, studies on pharmacokinetics/pharmacodynamics were not performed in our study.

In conclusion, the present study with dose escalation from $50 \mathrm{mg} /$ day to $75 \mathrm{mg} /$ day of naftopidil showed that $75 \mathrm{mg} /$ day of naftopidil was useful for alleviating storage, voiding, and postmicturition symptoms in men without compromising safety. The high score for slow stream at baseline and unsatisfactory improvement in nocturia with $50 \mathrm{mg} /$ day of naftopidil may be important factors for men with LUTS, who prefer and benefit from dose escalation of this agent. Further studies are warranted to elucidate the various effects of naftopidil for male LUTS.

\section{Conflict of Interests}

The authors declare no conflict of interests. This work has not been funded by any commercial company or organization. 


\section{Abbreviations}

LUTS: Lower urinary tract symptoms

BPH: Benign prostatic hyperplasia

IPSS: International Prostate Symptom Score.

\section{Acknowledgment}

The authors thank Ms. Noriko Sekine, Ms. Emiko Sato, Ms. Chieko Watanabe, and Ms. Eiko Honma for their enthusiastic nursing and assistance in data acquisition.

\section{References}

[1] P. Abrams, "New words for old: lower urinary tract symptoms for “ prostatism"”, British Medical Journal, vol. 308, no. 6934, pp. 929-930, 1994.

[2] P. Abrams, L. Cardozo, M. Fall et al., "The standardisation of terminology of lower urinary tract function: report from the standardisation sub-committee of the international continence society," Neurourology and Urodynamics, vol. 21, no. 2, pp. 167-178, 2002.

[3] P. Boyle, C. Robertson, C. Mazzetta et al., "The prevalence of lower urinary tract symptoms in men and women in four centres. The UrEpik study," BJU International, vol. 92, no. 4, pp. 409-414, 2003.

[4] N. Mittmann, K. Trakas, N. Risebrough, and B. A. Liu, "Utility scores for chronic conditions in a communitydwelling population," PharmacoEconomics, vol. 15, no. 4, pp. 369-376, 1999.

[5] C. J. Girman, S. J. Jacobsen, T. Tsukamoto et al., "Healthrelated quality of life associated with lower urinary tract symptoms in four countries," Urology, vol. 51, no. 3, pp. 428436, 1998.

[6] D. E. Irwin, I. Milsom, S. Hunskaar et al., "Population-based survey of urinary incontinence, overactive bladder, and other lower urinary tract symptoms in five countries: results of the EPIC study," European Urology, vol. 50, no. 6, pp. 1306-1315, 2006.

[7] Y. Homma, O. Yamaguchi, and K. Hayashi, "Epidemiologic survey of lower urinary tract symptoms in Japan," Urology, vol. 68, no. 3, pp. 560-564, 2006.

[8] R. I. Takei, I. Ikegaki, K. Shibata, G. Tsujimoto, and T. Asano, "Naftopidil, a novel $\alpha$-adrenoceptor antagonist, displays selective inhibition of canine prostatic pressure and high affinity binding to cloned human $\alpha$-adrenoceptors," Japanese Journal of Pharmacology, vol. 79, no. 4, pp. 447-454, 1999.

[9] K. Akiyama, H. Noto, O. Nishizawa et al., "Effect of KMD3213 , an $\alpha$-adrenoceptor antagonist, on the prostatic urethral pressure and blood pressure in male decerebrate dogs," International Journal of Urology, vol. 8, no. 4, pp. 177-183, 2001.

[10] Y. Nishino, T. Masue, K. Miwa, Y. Takahashi, S. Ishihara, and T. Deguchi, "Comparison of two $\alpha$-adrenoceptor antagonists, naftopidil and tamsulosin hydrochloride, in the treatment of lower urinary tract symptoms with benign prostatic hyperplasia: a randomized crossover study," BJU International, vol. 97, no. 4, pp. 747-751, 2006.

[11] K. Yasuda, T. Yamanishi, M. Tojo, K. Nagashima, S. Akimoto, and J. Shimazaki, "Effect of naftopidil on urethral obstruction in benign prostatic hyperplasia: assessment by urodynamic studies," Prostate, vol. 25, no. 1, pp. 46-52, 1994.
[12] Y. Funahashi, R. Hattori, Y. Matsukawa, T. Komatsu, N. Sassa, and M. Gotoh, "Clinical efficacy of a loading dose of naftopidil for patients with benign prostate hyperplasia," World Journal of Urology. In press.

[13] Y. Kojima, S. Sasaki, Y. Hayashi et al., "Correlation between alpha 1-adrenoreceptor subtype mRNA expression level and efficacy of naftopidil for BPH patients," Journal of Urology, vol. 171, p. 242, 2004.

[14] A. Komiya, H. Suzuki, Y. Awa et al., "Clinical effect of naftopidil on the quality of life of patients with lower urinary tract symptoms suggestive of benign prostatic hyperplasia: a prospective study," International Journal of Urology, vol. 17, no. 6, pp. 555-562, 2010.

[15] D. A. Schwinn and C. G. Roehrborn, " $\alpha$-Adrenoceptor subtypes and lower urinary tract symptoms," International Journal of Urology, vol. 15, no. 3, pp. 193-199, 2008.

[16] M. P. FitzGerald, H. J. Litman, C. L. Link, and J. B. McKinlay, "The association of nocturia with cardiac disease, diabetes, body mass index, age and diuretic use: results from the $\mathrm{BACH}$ survey," Journal of Urology, vol. 177, no. 4, pp. 1385-1389, 2007.

[17] M. C. Michel and W. Vrydag, "Alpha1-, alpha2- and betaadrenoceptors in the urinary bladder, urethra and prostate," British Journal of Pharmacology, vol. 147, pp. S88-119, 2006.

[18] H. Ishihama, Y. Momota, H. Yanase, X. Wang, W. C. De Groat, and M. Kawatani, "Activation of $\alpha$ adrenergic receptors in the rat urothelium facilitates the micturition reflex," Journal of Urology, vol. 175, no. 1, pp. 358-364, 2006.

[19] C. Hampel, P. C. Dolber, M. P. Smith et al., "Modulation of bladder $\alpha 1$-adrenergic receptor subtype expression by bladder outlet obstruction," Journal of Urology, vol. 167, no. 3, pp. 1513-1521, 2002.

[20] Q. Chen, S. Takahashi, S. Zhong et al., "Function of the lower urinary tract in mice lacking $\alpha$ - adrenoceptor," Journal of Urology, vol. 174, no. 1, pp. 370-374, 2005. 


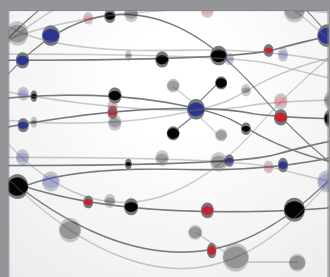

The Scientific World Journal
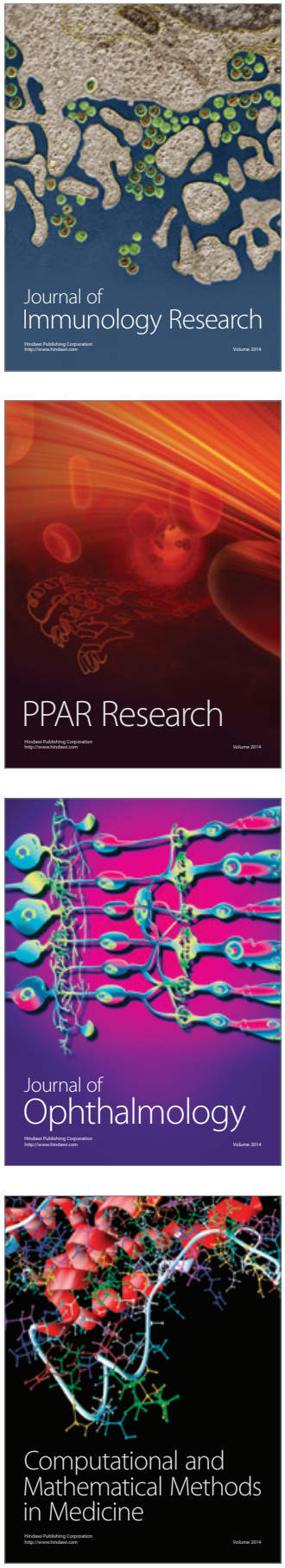

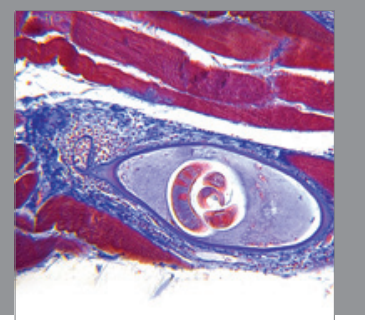

Gastroenterology

Research and Practice
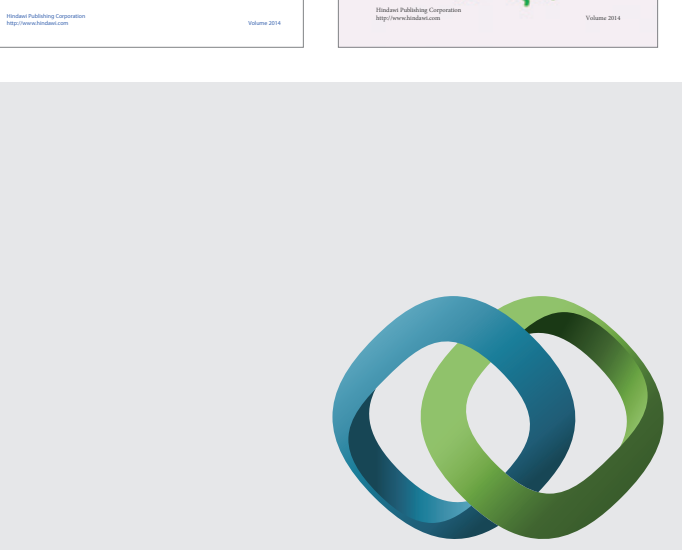

\section{Hindawi}

Submit your manuscripts at

http://www.hindawi.com
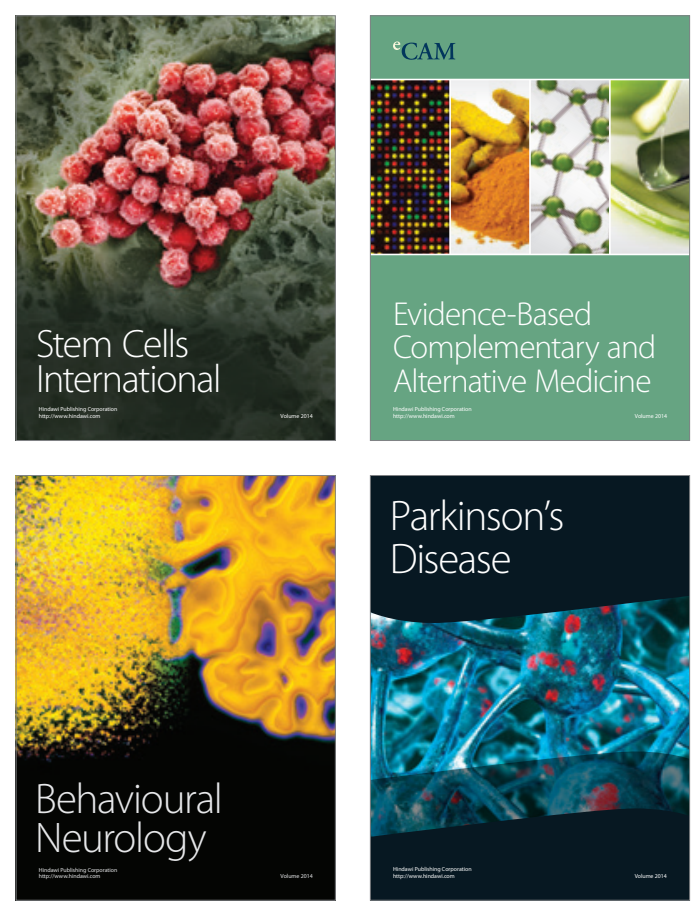

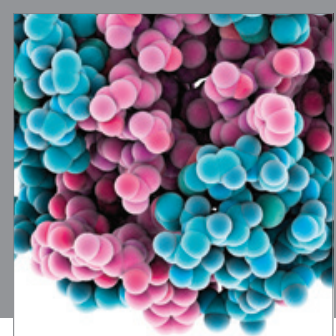

Journal of
Diabetes Research

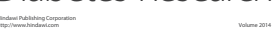

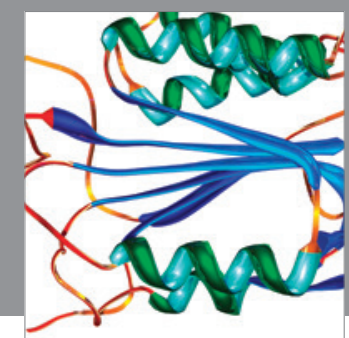

Disease Markers
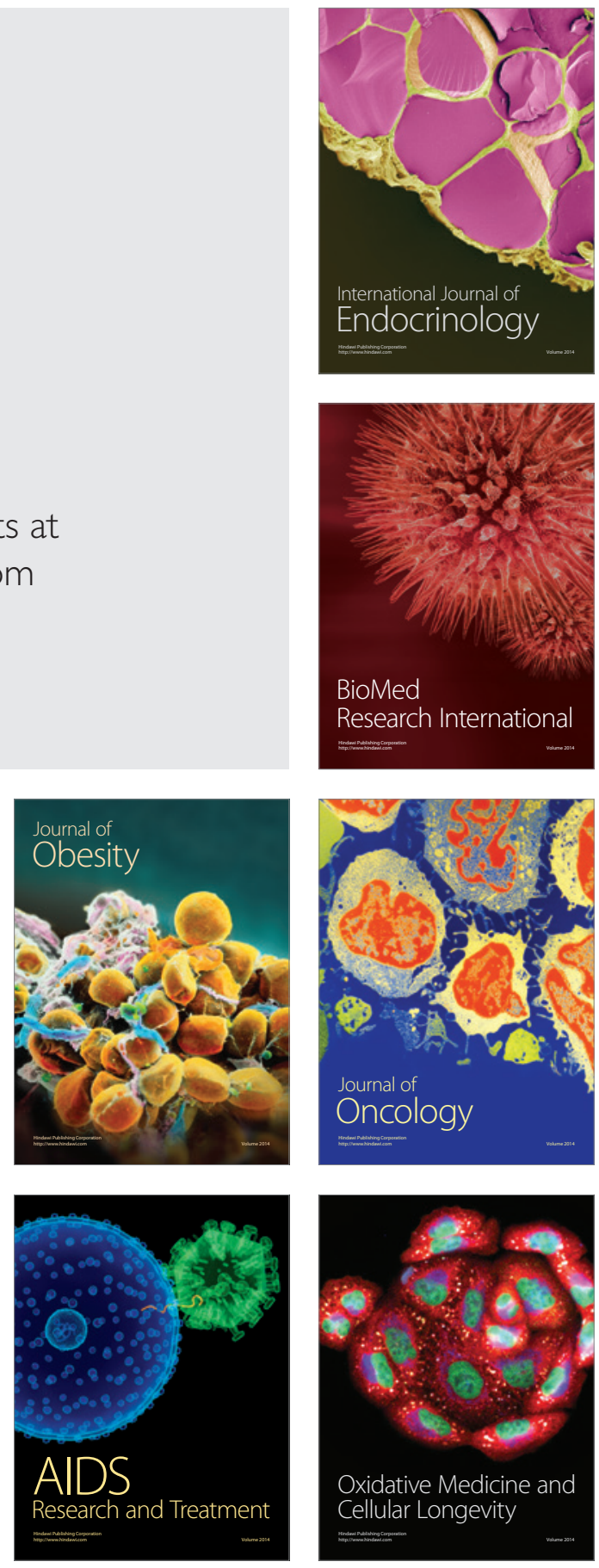